\section{Sports injury prevention: Mission Possible!}

\author{
Hilde Moseby Berge, ${ }^{1,2}$ Ben Clarsen ${ }^{1,3}$
}

\begin{abstract}
'Mission completed' could be the headline for Myklebust et al who tell the story of how the incidence of ACL injury among female handball players in Norway has been kept low, 10 years after the publication of their successful intervention study. ${ }^{1}$ An inspirational read, emphasising how a step-by-step approach combined with hard work and persistence, can make a difference (that matters). This issue highlights Norway's systematic, consistent and longterm approach to addressing key research areas: sports injury prevention, active rehabilitation, women's health and physical activity medicine. It also celebrates BJSM welcoming the Norwegian Association of Sports Medicine and Physical Activity (NIMF) and the Norwegian Sports Physiotherapy Association (FFI) as member societies; a partnership we are extremely proud of. Full text of BJSM is freely available to all Norwegian URL addresses, not just to society members.
\end{abstract}

\section{STEP-BY-STEP TOWARDS PREVENTION SUCCESS}

Since the establishment of Oslo Sports Trauma Research Centre (OSTRC) 13 years ago, its members have contributed to over 200 articles covering the various stages of systematic injury prevention research (figure 1). ${ }^{3}$ Examples of each stage can be found in this issue.

The first step, describing the extent of the problem, is covered by two of OSTRC's new focus areas: sports cardiology and overuse injuries. In their study of ambulatory blood pressure in footballers, Moseby Berge et al unmask how little we currently know about the prevalence of hypertension in athletes, while Clarsen et al present a novel method for registration of overuse injuries in epidemiological studies. The need for specific methods to study overuse issues was highlighted by Professor Roald Bahr in his

\footnotetext{
${ }^{1}$ Oslo Sports Trauma Research Center, The Norwegian School of Sport Sciences, Oslo, Norway; ${ }^{2}$ The

Norwegian Association of Sports Medicine and Physical Activity (NIMF); ${ }^{3}$ The Norwegian Sports Physiotherapy Association (FFI)

Correspondence to Dr Hilde Moseby Berge or Ben Clarsen, Oslo Sports Trauma Research Center, The Norwegian School of Sport Sciences, Sognsveien 220, PO Box 4014-Ullevaal Stadion, Oslo 0806, Norway; hilde.moseby.berge@nih.no or ben.clarsen@nih.no
}

opening keynote address at the Second World Congress on Sports Injury Prevention in Tromsø, Norway in 2008.

The second step in the sequence of injury prevention is to determine the causes of injury by analysing risk factors and injury mechanisms. Visnes et al report an interesting risk factor for development of jumper's knee; namely jumping ability! Meanwhile, our terrific cover image by computer animation specialist Oliver Faul highlights the techniques used by OSTRC researchers to determine injury mechanisms based on video analysis. ${ }^{4}$ These attractive animations are really helpful, but the editorial by Kristianslund et al reminds us to 'proceed with caution' when interpreting the results of biomechanics studies.

The third step in the sequence of prevention is to develop prevention strategies, and the fourth is to implement them and measure their efficacy. On this note, Bjørneboe et al demonstrate the effect of stricter rule enforcement on the number of injury situations in Norwegian professional football. This shows how referees may be important in reducing injury risk in the future, but only if they maintain the same strategy after the researchers have packed up and left. Therefore, the final steps of systematic prevention research involve investigating the implementation context. ${ }^{3}$ In this issue we have two papers representing the forefront of this field: Steffen et al investigate whether different methods of delivering the FIFA $11+$ programme affect team compliance and injury risk in youth football, while in their insightful editorial Donaldson and Finch 'drive' home an important message; the principles of implementation science should be applied to sports injury prevention in order to understand what does and does not work in the real world.

\section{IMPORTANT STEPS FOR WOMEN AND CHILDREN}

The relationship between physical activity and health is another key research area in Norway. In his editorial, Professor Sigmund Andersen draws attention to the challenge of fighting childhood obesity and to a school-based RCT published in $B J S M$ aimed at increasing physical activity among pupils. ${ }^{5}$ School-based interventions are promising, which is good news given the uncertainty of the effectiveness of primary-care referrals to promote physical activity, highlighted in the 'from the BMJ' article by Pavey et al. Meanwhile, Gjestland et al provide encouraging evidence of the value of exercise during pregnancy, even if the current exercise recommendations are far from followed.

Finally, Moksnes et al report the results of a 6-year cohort study of ACL-injured children. Their findings may have substantial implications on clinical practice in this field, something we have almost come to expect from the prolific group at the Norwegian Research Center for Active Rehabilitation (http://www.nar.no). You can look forward to several new articles in BJSM from members of NAR, as well as a podcast, in the near future.

Figure 1 A systematic approach to sports injury prevention. The original four-step model was described by van Mechelen et al in 1992, ${ }^{2}$ and later expanded by Finch. ${ }^{3}$ 


\section{'OUTROSPECTIVE'}

Looking over the 'Norwegian' articles in this edition, it is worth noting that almost a third of the authors are not from Norway. This highlights the strong commitment to international collaboration, as well as the increasingly diverse cultural mix within our milieu. Every day we (1 Norwegian and 1 Australian) sit alongside researchers from all corners of the globe, and it seems that at all times some of our colleagues are on international exchange. This bodes well for the mission of sports and exercise medicine research in Norway!

We hope you enjoy this edition of BJSM and welcome suggestion from both inside and outside Norway as to making the 2014 issue even more relevant for you!

\section{Competing interests None.}

Provenance and peer review Not commissioned; internally peer reviewed.

To cite Berge HM, Clarsen B. Br I Sports Med 2013;47:467-468.

Accepted 22 March 2013

Br J Sports Med 2013;47:467-468

doi:10.1136/bjsports-2013-092457

\section{REFERENCES}

1 Myklebust G, Engebretsen L, Braekken IH, et al. Prevention of anterior cruciate ligament injuries in female team handball players: a prospective intervention study over three seasons. Clin I Sport Med 2003;13:71-8.

2 Van Mechelen W, Hlobil H, Kemper HC. Incidence, severity, aetiology and prevention of sports injuries. A review of concepts. Sports Med 1992;14:82-99.

3 Finch C. A new framework for research leading to sports injury prevention. J Sci Med Sport 2006;9: 3-9.

4 Krosshaug T, Bahr R. A model-based image-matching technique for three-dimensional reconstruction of human motion from uncalibrated video sequences. J Biomech 2005;38:919-29.

5 Grydeland M, Bielland M, Anderssen S. Promoting healthy weight in school children: what does the HEIA study teach us about effective interventions? Br J Sports Med 2013 (in press). 